\title{
Dietary sesame (Sesamum indicum cultivar Linn) oil inhibits iron-induced oxidative stress in rats
}

\author{
S. Hemalatha, M. Raghunath and Ghafoorunissa* \\ National Institute of Nutrition, Indian Council of Medical Research, Jamai Osmania P. O., Hyderabad-500 007. A. P., India \\ (Received 21 January 2004 - Revised 20 May 2004 - Accepted 11 June 2004)
}

\begin{abstract}
The high stability of sesame oil against oxidative deterioration is attributed to lignans in its non-glycerol fraction. The present study evaluates the effects of feeding sesame lignans (sesamin and sesamolin) on $\mathrm{Fe}^{2+}$-induced oxidative stress in rats. Three groups, each of sixteen male weanling WNIN rats, were fed diets containing $200 \mathrm{~g}$ casein/ $\mathrm{kg}$ and $100 \mathrm{~g}$ oil $/ \mathrm{kg}$ (group 1, groundnut oil; group 2, sesame oil; group 3, sesame oil + sesamin $(0.4 \mathrm{~g} / \mathrm{kg})$. After $45 \mathrm{~d}$ of feeding, eight rats from each group were injected with saline $(9 \mathrm{~g} \mathrm{Na} \mathrm{Cl} / \mathrm{l}$, controls) intraperitoneally while the remaining eight rats were injected with $30 \mathrm{mg} \mathrm{Fe}{ }^{2+} / \mathrm{kg}$ body weight as ferrous sulfate in normal saline. The animals were killed after $90 \mathrm{~min}$ to evaluate hepatic function and antioxidant status. Compared with those fed groundnut oil (group 1), sesame oil-fed rats (groups 2 and 3) had lower levels of hepatic thiobarbituric acid-reactive substances, serum glutamate:oxaloacetate transaminase activities and serum glutamate pyruvate transaminase activities, indicating protection against Fe-induced oxidative stress. Despite similar tocopherol levels in the three diets, hepatic $\alpha$-tocopherol levels were higher in rats fed the sesame-oil diets (groups 2 and 3) compared with controls (group 1). However, activities of hepatic antioxidant enzymes (superoxide dismutase and glutathione peroxidase) were significantly $(P<0 \cdot 05)$ increased only in rats fed higher levels of lignans (group 3). These observations suggest that sesame lignans may have sparing effects on tocopherols. The increased bioavailability of tocopherols in the presence of dietary lignans might be due to the regeneration of oxidized tocopherols. The synergistic effects of lignans with tocols has nutritional and therapeutic implications.
\end{abstract}

Sesame lignans: Sesamin: Sesamolin: Iron-induced oxidative stress in vivo: Antioxidant effects

Sesame (Sesamum indicum) has long been categorized as a traditional health food in India and Asian countries. Budowski \& Markley (1951) and Meydani (1992) reported that consumption of sesame oil can delay the process of ageing. Topical application of sesame oil has been practised for centuries (Press et al. 1974). However, the scientific basis underlying the medicinal effects of sesame oil are not well understood. Recently sesamin, the major lipid soluble component of sesame seed unsaponifiables has been shown to exert diverse physiological functions (Hirose et al. 1992; Sugano \& Akimoto, 1993; Matsumura et al. 1995, 1998) including hypocholesterolaemic effects in human subjects (Hirata et al. 1996). Sesamin (5 and $10 \mathrm{~g} / \mathrm{kg}$ ) has been shown to have hypocholesterolaemic and antihypertensive effects, to protect the liver from damage induced by alcohol, and to protect against $\mathrm{CCl}_{4^{-}}$and 1,2 dimethylbenz[a]anthraceneinduced rat mammary carcinogenesis (Hirose et al. 1992). Sesamolin, the second major sesame lignan, has been shown to inhibit proliferation by inducing apoptosis in human lymphoid leukaemia Molt 4B cells (Miyahara et al. 2001). Sesamolin $(10 \mathrm{~g} / \mathrm{kg})$ is metabolized to sesamol and sesamolinol in vivo and inhibits lipid peroxidation (Kang et al. 1998). Sesamol and sesaminol, the degradation products of sesamolin, have also been shown to inhibit the formation of lipid peroxides in the oil and contribute to the higher stability of sesame oil (Fukuda et al. 1986a,b). Thus, it is evident from literature that the physiological effects of sesame lignans have been demonstrated at much greater supplementary levels than their consumption through dietary sources.

In an attempt to evaluate the antioxidant effects of individual sesame lignans, sesamin and sesamolin were isolated and crystallized from an Indian sesame cultivar with a high lignan content (Sesamum indicum cultivar Linn; Hemalatha \& Ghafoorunissa, 2004). Using in vitro lipid peroxidation systems, we showed that sesame lignans potentiate the inhibitory effects of tocopherols and tocotrienols (Ghafoorunissa et al. 2004). The present study was conducted to evaluate whether feeding sesame oil $(1.2-1.6 \mathrm{~g}$ lignans $/ \mathrm{kg}$ sesame seed or oil) to rats modulates oxidative stress and antioxidant status against $\mathrm{Fe}$-induced oxidative damage.

\section{Materials and methods}

Chemicals

Reduced NADPH, GSSG, GSH, glutathione reductase, cumene hydroperoxide, butylated hydroxytoluene,

\footnotetext{
Abbreviations: SGOT, serum glutamate:oxaloacetate transaminase; SGPT, serum glutamate pyruvate transaminase; TBARS, thiobarbituric acid-reactive substances.

*Corresponding author: Dr Ghafoorunissa, fax + 9140 27019074, email ghafoorunissanin@ rediffmail.com and ghafoorunissanin@yahoo.com
} 
thiobarbituric acid, tetraethoxypropane, pyrogallol, tocopherols ( $\alpha$ - and $\gamma-)$ and sesamol were from Sigma Chemical Co. (St Louis, MO, USA). $\mathrm{H}_{2} \mathrm{O}_{2}$ was obtained from E-Merck (Mumbai, India) and diethylene triamine penta acetic acid was from Loba Chemie (Mumbai, India). Assay kits for serum glutamate oxaloacetate transaminase (SGOT), serum glutamate pyruvate transaminase (SGPT) and HPLC solvents were obtained from Qualigens India Ltd (Mumbai, India). All other chemicals used were of analytical grade procured from local sources.

Sesamin was isolated and crystallized from a high-lignan sesame variety (Hemalatha \& Ghafoorunissa, 2004) according to Budowski (1950) and purified by recrystallization in absolute ethyl alcohol. Groundnut oil (DharaNational Dairy Development Board, Anand, Gujarat, India) and sesame oil (Agmark label; Mansion brand; Samalkot, Andhra Pradesh, India) were purchased from the local market.

\section{Animals, diets and study design}

The Institute's Animal Ethics committee approved the animal experimental protocols. The institutional guidelines for the care and use of laboratory animals were followed strictly. Male weanling WNIN rats with a mean body weight of $35 \mathrm{~g}$ ( $n$ 48) were obtained from the National Centre for Laboratory Animal Sciences at the National Institute of Nutrition, Hyderabad, India. Rats were randomly divided into three groups (sixteen per group; a control group and two experimental groups) and housed individually in polypropylene cages at a temperature of $24 \pm 2{ }^{\circ} \mathrm{C}$ and with a $12 \mathrm{~h}$ light-dark cycle. Rats were fed ad libitum (Table 1; $200 \mathrm{~g}$ casein $/ \mathrm{kg}, 100 \mathrm{~g}$ oil $/ \mathrm{kg}$ (group 1, groundnut oil; group 2, sesame oil; group 3, sesame oil + sesamin $(0.4 \mathrm{~g} / \mathrm{kg}))$. The total tocopherol content was similar in all three diets and the diets differed only in their lignan content (Table 1). Although the total PUFA composition and SFA content were similar in the groundnut- and sesame-oil groups, the two oils differed in their individual SFA contents (Table 2).

Dietary intakes were recorded daily and body weights were monitored once per week. After $45 \mathrm{~d}$ of feeding, animals were fasted overnight and oxidative stress was

Table 1. Composition of diets $(\mathrm{g} / \mathrm{kg})$

\begin{tabular}{lccc}
\hline Ingredients & Group $1^{*}$ & Group 2* & Group 3* \\
\hline Casein & 200 & 200 & 200 \\
Cellulose & 50 & 50 & 50 \\
Starch & 600 & 600 & 600 \\
Choline chloride & 2 & 2 & 2 \\
Methionine & 3 & 3 & 3 \\
Vitamin mix† & 10 & 10 & 10 \\
Mineral mix & 35 & 35 & 35 \\
Oilł & 100 & 100 & 100 \\
$\alpha$-Tocopherol & 0.03 & - & - \\
$\gamma$-Tocopherol & 0.04 & 0.07 & 0.07 \\
Sesamin & 0.0 & 0.8 & 1.2 \\
Sesamolin & 0.0 & 0.4 & 0.4 \\
\hline
\end{tabular}

* Group 1, groundnut oil; group 2, sesame oil; group 3, sesame oil + sesamin ( $0.4 \mathrm{~g} / \mathrm{kg}$ diet).

†Prepared as per AIN formulations (Reeves et al. 1993).

$\ddagger$ Groundnut oil or sesame oil or sesame oil + sesamin $(0.4 / \mathrm{kg}$ diet).
Table 2. Fatty acid composition of oils $(\mathrm{g} / 100 \mathrm{~g}$ total fatty acids)

\begin{tabular}{llcc}
\hline Serial no. & Fatty acids & Groundnut oil & Sesame oil \\
\hline 1 & $16: 0$ & $13 \cdot 0$ & $8 \cdot 0$ \\
2 & $18: 0$ & $3 \cdot 3$ & $10 \cdot 0$ \\
3 & $20: 0$ & $2 \cdot 1$ & - \\
4 & $24: 0$ & $4 \cdot 9$ & $0 \cdot 2$ \\
5 & $18: 1$ & $44 \cdot 0$ & $43 \cdot 0$ \\
6 & $18: 2 n-6$ & $33 \cdot 0$ & $38 \cdot 0$ \\
\hline
\end{tabular}

induced in eight rats per group by a single intraperitoneal injection of $30 \mathrm{mg} \mathrm{Fe}{ }^{2+}$ as ferrous sulfate in normal saline $(9 \mathrm{~g} \mathrm{NaCl} / \mathrm{l}) / \mathrm{kg}$ body weight (Hu et al. 1990). The remaining eight rats in each group were injected with normal saline and served as controls.

\section{Blood and tissue collections}

Blood was collected from the orbital sinus 90 min after the intraperitoneal injection of ferrous sulfate and before killing; serum was separated and stored at $-70^{\circ} \mathrm{C}$ until further analysis. Rats were killed by $\mathrm{CO}_{2}$ inhalation, the abdomen was cut open quickly and the liver perfused thoroughly with isotonic saline $(9 \mathrm{~g} \mathrm{NaCl} / \mathrm{l})$, excised, blotted dry and divided into multiple samples. One of the samples was used to assess the thiobarbituric acid-reactive substances (TBARS) in the liver homogenate on the same day, while the other samples were quickly frozen in liquid $\mathrm{N}_{2}$ and stored at $-70^{\circ} \mathrm{C}$.

\section{Tissue processing}

Livers collected from each rat were homogenized in $10 \mathrm{~mm}$-Tris- $\mathrm{HCl}$ buffer, $\mathrm{pH} 7.4$ containing $0.2 \mathrm{~mol} \mathrm{KCl} / 1$, using a Polytron homogenizer (Kinematica, Lucerne, Switzerland) for $2 \mathrm{~min}$ at $4^{\circ} \mathrm{C}$. The homogenate was subjected to differential centrifugation (Sorval OTD-65B ultracentrifuge using 50.1 type rotor; Newtown, CT, USA) at $800 \mathrm{~g}$ for $10 \mathrm{~min}, 14000 \mathrm{~g}$ for $10 \mathrm{~min}, 105000 \mathrm{~g}$ for $80 \mathrm{~min}$ at $4^{\circ} \mathrm{C}$; the supernatant fractions were collected and stored frozen at $-70^{\circ} \mathrm{C}$ until further analysis. The protein contents of these supernatant fractions were determined according to a modified Lowry's method (Schacterle \& Pollack, 1973).

\section{Tocopherols in liver homogenate}

Total lipids were extracted (Bligh \& Dyer, 1959) from liver homogenate (corresponding to about $10 \mathrm{mg}$ protein), reconstituted in $50 \mu l n$-hexane and mixed well; a $20 \mu l$ sample was analysed for tocol profile by reverse-phase HPLC (Shimadzu LC-10A HPLC system; Chiyoda-ku, Tokyo, Japan), using a Shodex $\mathrm{C}_{18}$ column (4.6 mm internal diameter $\times 250$ $\mathrm{mm}$; Shodex, Minat-ku, Tokyo, Japan) connected to a manual valve injector and a Shimadzu UV-Vis detector SPD-10A (Shimadzu). The mobile phase comprised acetonitrile-methanol-dichloromethane (60:35:5, by vol.) at a flow rate of $2 \mathrm{ml} / \mathrm{min}$ (Barrie \& Linda, 1989). The chromatograms were recorded in a Shimadzu C-R6A Chromatopac and the peaks quantified by comparison with those of authentic tocols ( $\tilde{\alpha}, \gamma$ - and $\tilde{\delta}$-tocopherol, and $\alpha$-tocotrienol) used as external standards. 


\section{Lipid peroxidation}

The lipid peroxide content in liver homogenate was measured as TBARS (Slater \& Sawyer, 1971) using $1,1,3,3$ tetraethoxypropane as an authentic external standard.

\section{Antioxidant enzymes}

Catalase. The activity of catalase was determined in the supernatant fraction of liver homogenate $(800 \mathrm{~g}, 50-$ $100 \mu \mathrm{g}$ protein) by following the decomposition of $\mathrm{H}_{2} \mathrm{O}_{2}$ at $240 \mathrm{~nm}$ for $1 \mathrm{~min}$ (Aebi, 1983).

Superoxide dismutase. Superoxide dismutase was assayed in the supernatant fraction $(105000 \mathrm{~g}, 200-300 \mu \mathrm{g}$ protein) by following the inhibition of auto-oxidation of pyrogallol at $420 \mathrm{~nm}$ for $1 \mathrm{~min}$ (Marklund \& Marklund, 1974).

Glutathione peroxidase. Glutathione peroxidase was assayed in the supernatant fraction $(105000 \mathrm{~g}, 100-200 \mu \mathrm{g}$ protein) using cumene hydroperoxide as the substrate. The activity was expressed as the amount of NADPH oxidized in $1 \mathrm{~min}$ at $340 \mathrm{~nm}$ (Paglia \& Valentine, 1967).

\section{Statistical analysis}

All the results are expressed as mean values with their standard errors for six to eight independent observations, with all measurements being performed in duplicate. Data were analysed for statistical significance by two-way ANOVA using the SPSS statistical package (version 10.0; SPSS Inc., Chicago, IL, USA). Post hoc multiple comparison tests for significant differences among groups using least significant difference were performed only for oils. Similar post hoc tests were not performed for stress, because there were only two stress conditions, i.e. with and without stress. The values were considered significantly different if $P$ values were $<0.05$.

\section{Results}

Diet intake, weight gain and liver weights

There were no significant differences in food intake, body weight gain or liver weights among the three groups of rats (results not shown).

\section{Serum enzymes}

Under basal conditions, feeding sesame-oil diets (groups 2 and 3) significantly decreased the SGPT (Fig. 1(B)) activity compared with groundnut-oil diets (group 1). The decrease in SGOT activity (Fig. 1(A)) was, however, significant $(P<0.05)$ only in rats fed the sesame-oil + sesamin diet (group 3) compared with rats fed the groundnut-oil (group 1) and sesame-oil (group 2) diets. Regardless of the type of oil fed, induction of oxidative stress with Fe caused a significant increase in the activities of SGOT and SGPT. Even under the conditions of Fe-induced oxidative stress, the activities of SGOT and SGPT (Fig. 1) were least in group 3, whereas the activities in groups 2 and 3 were not different from one another.
(A)

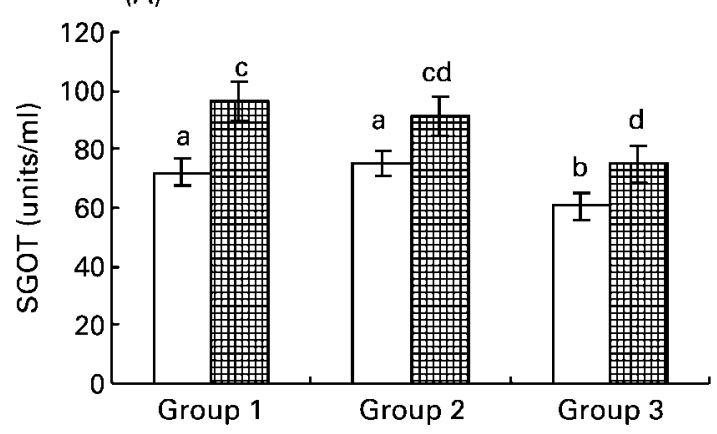

(B)

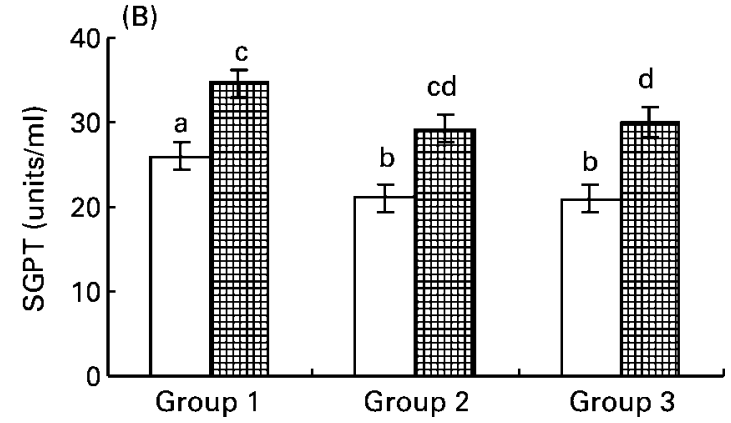

Fig. 1. Liver function tests in rats fed groundnut oil (group 1), sesame oil (group 2) and sesame oil + sesamin (group 3) diets, without $(\square)$ and with (嘼) Fe-induced oxidative stress. (A), serum glutamate oxalate transaminase (SGOT); (B) serum glutamate pyruvate transaminase (SGPT). Values are means with their standard errors for six to eight samples analysed. For details of diets and procedures, see p. 582. Data were analysed by two-way ANOVA followed by post hoc analysis using LSD. (A), SGOT: $F$ ratio for oils $3.324(P<0.05)$, stress $9.628(P<0.05)$; $(\mathrm{B})$, SGPT: $F$ ratio for oils $5.281(P<0.05)$, stress $13.574(P<0.05)$. a,b,c,d Mean values with unlike superscript letters were significantly different among the three groups under basal and Fe-induced stress conditions $(P<0.05)$

\section{Lipid peroxidation in hepatic tissue}

Basal levels of TBARS (Fig. 2(A)) in liver homogenates were comparable among the three groups, whereas induction of oxidative stress resulted in a twofold increase in TBARS in rats fed the groundnut-oil (group 1) diet $(P<0.05)$, no such increase was observed in rats fed the sesame-oil diets (groups 2 and 3 ).

\section{Tocopherol content in liver}

Basal levels of tocopherol in liver (Fig. 2(B)) were significantly higher $(P<0.05)$ in rats fed the sesame-oil diets (groups 2 and 3 ) than those receiving the groundnut-oil (group 1) diet. However, there was no difference between the hepatic tocopherol concentrations of rats fed diets containing sesame oil (groups 2 and 3). Induction of oxidative stress with $\mathrm{Fe}^{2+}$ did not cause significant changes in the hepatic tocopherol concentrations in any of the groups.

\section{Antioxidant enzymes}

There were no significant differences among the three groups of rats in the basal activities of catalase, superoxide dismutase and glutathione peroxidase in liver (Fig. 3). In addition, 


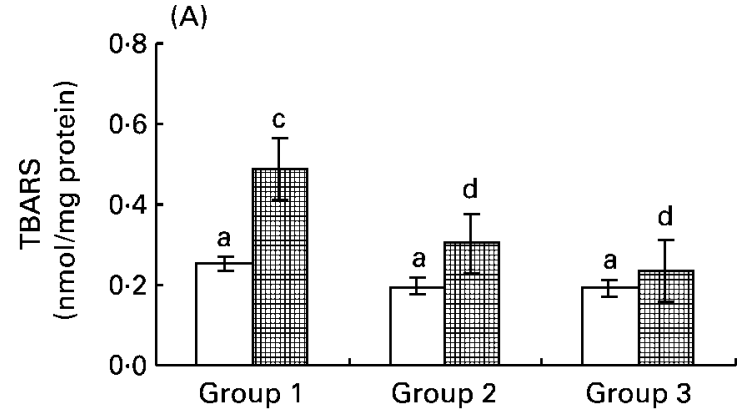

(B)

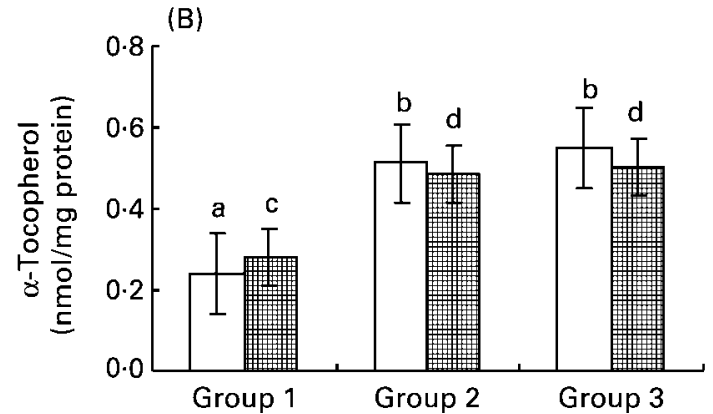

Fig. 2. Oxidative stress and antioxidant status of rats fed groundnut oil (group 1), sesame oil (group 2) and sesame oil + sesamin (group 3) diets, without ( $\square$ ) and with (怔) Fe-induced oxidative stress. (A), thiobarbituric acid-reactive substances (TBARS) in liver homogenate; (B), $\alpha$-tocopherol in liver homogenate. Values are means with their standard errors for six to eight samples analysed. For details of diets and procedures, see p. 582. Data were analysed by two-way ANOVA followed by post hoc analysis using LSD. (A), TBARS: $F$ ratio for oils $4.71(P<0.05)$, stress $8.56(P<0.05)$; $(\mathrm{B})$, $\alpha$-tocopherol: $F$ ratio for oils $12.48(P<0.05)$, stress 0.05 (NS). $\mathrm{a}, \mathrm{b}, \mathrm{c}, \mathrm{d}$ Mean values with unlike superscript letters were significantly different among the three groups under basal and Fe-induced stress conditions $(P<0.05)$.

induction of oxidative stress with $\mathrm{Fe}^{2+}$ did not cause any significant increase in the activities of these enzymes in any group of rats. A significant increase $(P<0.05)$ was observed in the superoxide dismutase and glutathione peroxidase activities in rats fed the diet containing sesame oil + sesamin (group 3) compared with those fed the groundnut- or sesameoil diets (groups 1 and 3).

\section{Discussion}

Fe overload leads to chronic hepatotoxicity, resulting in increased oxidative stress (Niederau et al. 1985). The present study demonstrates the effects of sesame lignans included in the diets of rats subjected to oxidative stress with $\mathrm{Fe}^{2+}$. A dose of $30 \mathrm{mg} \mathrm{Fe}{ }^{2+} / \mathrm{kg}$ body weight is the maximum concentration reported to be tolerated by rodents (Hu et al. 1990) and has been shown to induce hepatotoxicity (Bhattacharya et al. 2000). However, in the present study $30 \mathrm{mg} \mathrm{Fe}{ }^{2+}$ induced moderate hepatotoxicity, as assessed by SGOT and SGPT activities.

Feeding sesamin to rats at $2-5 \mathrm{~g} / \mathrm{kg}$ has been shown to increase liver weight (Sugano et al. 1990; Fujiwara et al. 1995; Gu et al. 1995, 1998; Nakabayashi et al. 1995; Yamashita et al. 1995). However, in the present study liver weights remained unaltered in rats fed the sesameoil diets $(1.2-1.6 \mathrm{~g}$ sesamin + sesamolin $/ \mathrm{kg})$, as has been

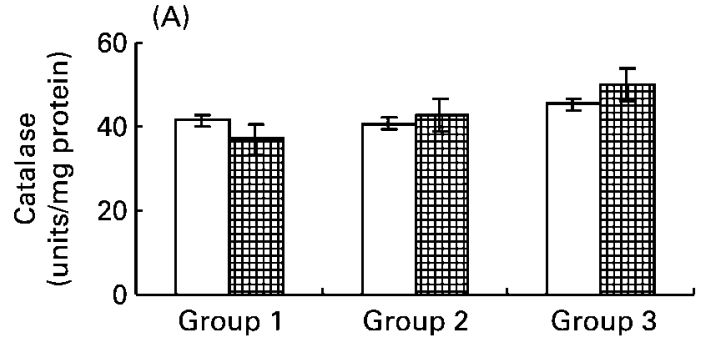

(B)
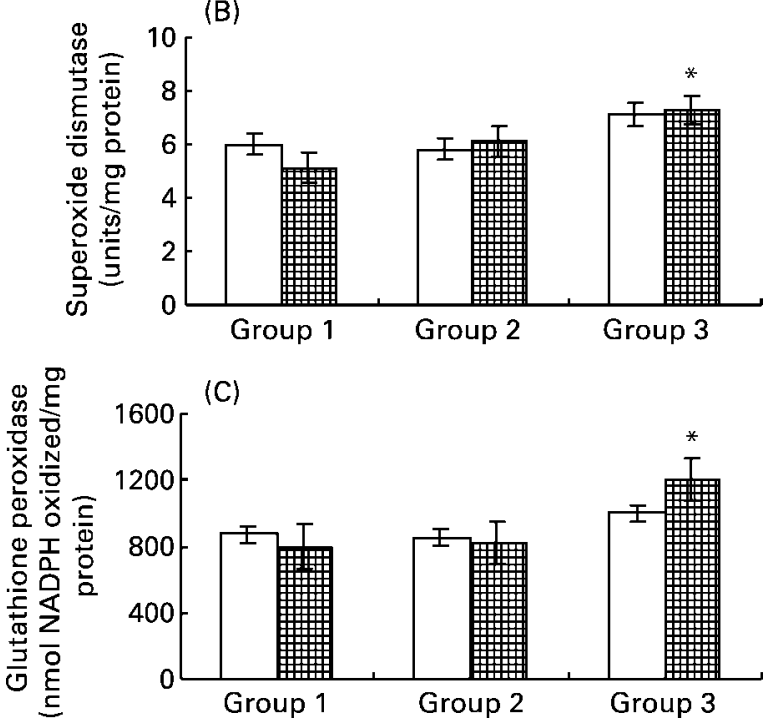

Fig. 3. Antioxidant enzyme activities in rats fed groundnut oil (group 1), sesame oil (group 2) and sesame oil + sesamin (group 3) diets,

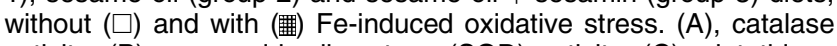
activity; (B), superoxide dismutase (SOD) activity; (C), glutathione peroxidase (Gpx) activity. Values are means with their standard errors for six to eight samples analysed. For details of diets and procedures, see p. 582. Data were analysed by two-way ANOVA followed by post hoc analysis using LSD. (A), catalase: $F$ ratio for oils 1.796 (NS), stress 0.041 (NS); (B), SOD: $F$ ratio for oils 4.364 $(P<0.05)$, stress 0.112 (NS); $(C)$, Gpx: $F$ ratio for oils 3.24 $(P<0.05)$, stress 0.197 (NS). Mean values were significantly different from those of groups 1 and $2:{ }^{*} P<0.05$.

reported by Kamal-Eldin et al. (1995) and Satchithanandam et al. (1996). Under basal and $\mathrm{Fe}^{2+}$-induced oxidative stress conditions, SGOT and SGPT activities were lower in rats fed the sesame-oil + sesamin diets (group 3). These observations suggest that dietary lignans provided through consumption of sesame seeds or oil may protect the liver against $\mathrm{Fe}$-induced oxidative damage. Akimoto et al. (1993) showed that sesamin lowered the ethanol inhalation-induced increase in SGPT activity. It has been shown that lignans (schisantherin compounds) containing the methylenedioxy group protect the liver from injury against viral hepatitis (as evident from lower SGPT levels) in mice and human subjects (Macrae \& Towers, 1984; Gao \& Rao, 1993). Therefore, the hepatoprotective effects of sesame oil observed in the present study could be due to the methylenedioxy group present in sesame lignans (sesamin and sesamolin). However, the mechanism needs to be studied.

Sesamin at $2 \mathrm{~g} / \mathrm{kg}$ has been shown to maintain blood and hepatic $\gamma$-tocopherol concentrations, resulting in enhanced suppression of lipid peroxidation (Yamashita et al. 1992, 
1995). Sesamin $(2 \mathrm{~g} / \mathrm{kg})$ and $\alpha$-tocopherol have also been shown to synergistically suppress lipid peroxidation in rats fed a high-docosahexaenoic acid diet (Yamashita et al. 2000). Kang et al. (1998) have shown that the concentration of TBARS in the liver and kidney of rats fed $10 \mathrm{~g}$ sesamolin $/ \mathrm{kg}$ diet was low. In the present study, rats fed the sesame-oil diet (group 3; $0.8 \mathrm{~g}$ sesamin $+0.4 \mathrm{~g}$ sesamolin $/ \mathrm{kg}$, a dose of sesamin that is about $50 \%$ of that reported by Yamashita et al. $(1992,1995))$ had maximum protection against $\mathrm{Fe}^{2+}$-induced lipid peroxidation; this appears to be due to the increase in hepatic $\alpha$-tocopherol (Fig. 2(B)). Therefore, the protection afforded by rats fed the sesame-oil diets (groups 2 and 3) may be due to the combined effects of sesamin and sesamolin. However, in response to Fe-induced stress, levels of TBARS in group 1 rats (control) were two- to threefold lower than those reported by Pulla Reddy \& Lokesh (1994). Further, regardless of the source of dietary oil, $\alpha$-tocopherol was the major isomer in liver (Fig. 2) of rats, while $\gamma$-tocopherol was present only in negligible amounts (results not shown). Yamashitha et al. (1995) reported that $\alpha$-tocopherol was the predominant isomer in serum and tissues of rats fed adequate $\alpha$-tocopherol and sesame diets, while $\gamma$-tocopherol was detected in rats fed deficient or low levels of $\alpha$-tocopherol.

Vitamin C and/or GSH in blood and tissues regenerates oxidized tocopherol to its native form (Leung et al. 1982; Scholz et al. 1997). The enhancement of vitamin E activity in vivo by food components has also been reported (Leung et al. 1982; Zhu et al. 2000). Sesame lignans have been shown to increase tissue tocopherol levels (Parker et al. 2000) by inhibition of the cytochrome P450 3A-dependent $n$-hydroxylase pathway of tocopherol catabolism. Recently, Yamashita et al. (2002) have shown that a sesaminolinduced increase in $\alpha$-tocopherol and $\alpha$-tocotrienol in plasma and tissues was not due to their enhanced absorption. In the present study, despite similar tocopherol levels in all three diets, the increased bioavailability of $\alpha$-tocopherol (Fig. 2(B)) in the presence of dietary lignans (groups 2 and 3) appears to be due to inhibition of tocopherol catabolism and/or regeneration of oxidized tocopherols.

Antioxidant enzymes have an important role in the secondary defence mechanism during oxidative stress. In the present study, although the activity of catalase was not affected by the dietary oils or by the induction of oxidative stress with $\mathrm{Fe}^{2+}$, superoxide dismutase activity was greater in rats fed sesame oil + sesamin (group 3). These results suggest that sesame lignans may enhance the ability to 'mop up' superoxide radicals formed during $\mathrm{Fe}^{2+}$. induced oxidative stress. Induction of oxidative stress with $\mathrm{Fe}^{2+}$ caused an increasing trend in glutathione peroxidase activity only in group 3 . The observation that the hepatic antioxidant enzyme (superoxide dismutase and glutathione peroxidase) activities were significantly higher $(P<0.05)$ in rats fed diets containing sesame oil + sesamin (group 3) than in those fed sesame-oil diets (group 2) supports the dose-dependent effects of dietary sesame lignans on the antioxidant enzyme activities. Sesame antioxidants (sesamin and sesamolin) spared superoxide dismutase and catalase in hypoxia-stressed
PC12 cells in a dose-dependent manner, an effect that may be related to their radical scavenging effect (Hou et al. 2003). Earlier studies have shown the effects of sesame lignans (sesamin and sesamolin) on antioxidant enzyme activities in in vitro systems using cell lines (Hou et al. 2003), whereas in the present study these effects were demonstrated in vivo.

The degradation products of sesamin in liver (Asami et al. 1993) and the metabolites of sesamolin (sesamol and sesamolinol) have been shown to contribute to their antioxidant effects in vivo (Kang et al. 1998). Using various lipid peroxidation systems, Uchida et al. (1996) showed that sesamol and related compounds containing methyelene dioxy groups have antioxidant effects. Sesamin and sesamolin inhibited lipid peroxidation in vitro in the enzymic and non-enzymic lipid peroxidation systems only when incubated with microsomes, and not with mitochondria or boiled microsomes (Ghafoorunissa et al. 2004); this suggests that the metabolites of these lignans may have greater antioxidant activities. Earlier, the synergistic effects of sesamin $(2 \mathrm{~g} / \mathrm{kg})$ and tocopherols in increasing the bioavailability of $\gamma$-tocopherol (Kamal-Eldin et al. 1995), in inducing hypocholesterolaemia (Nakabayashi et al. 1995) and in modulating immune functions (Gu et al. 1997) have been documented. Our earlier studies have shown that sesame lignans (sesamol, sesamin and sesamolin) potentiate the antioxidant activities of tocols ( $\tilde{\alpha}$ or $\gamma$-tocopherol or $\alpha$-tocotrienol) in lipid peroxidation systems in vitro (Ghafoorunissa et al. 2004). The findings of our in vitro study and the present observations suggest that sesame oil (1.0-1.5 g sesamin + sesamolin/ $\mathrm{kg}$ ) consumed through dietary sources, along with tocopherols, may counteract the oxidative damage caused by reactive oxygen species during $\mathrm{Fe}^{2+}$-induced oxidative stress. This could be due to the metabolites of sesame lignans and/or tocopherol enhancing effects of sesame lignans.

Since reactive oxygen species are implicated in chronic diseases, current emphasis is to identify newer natural components of food exhibiting antioxidant activity. Considering the widespread production and usage of sesame oil and consumer preference for natural antioxidants, sesame seeds and oil appear to be promising agents with therapeutic potential. However, the mechanism(s) of the antioxidant and hepatoprotective effects of sesame lignans in vivo, vis-à-vis the increased levels of tocopherols and increased antioxidant enzyme activities needs to be deciphered.

\section{References}

Aebi HE (1983) Catalase. In Methods in Enzymatic Analysis, vol III, pp. 273-282 [HU Bergmeyer, editor]. Weinhein: Verlog Chemie.

Akimoto K, Kitagawa Y, Akamatsu T, Hirose N, Sugano M, Shimizu S \& Yamada H (1993) Protective effects of sesamin caused by alcohol or carbon tetra chloride in rodents. Ann Nutr Met 37, 218-224.

Asami S, Akimoto K, Abe K, Akamatsu T, Konishi K, Shimizu S, Sugano M \& Yamada H (1993) Antioxidant activity of sesamin on NADPH dependent lipid peroxidation in liver microsomes. Nippon Nogeikagaku Kaishi 67, 265.

Barrie T \& Linda B (1989) Separation of tocopherol and 
tocotrienol isomers using normal and reverse phase liquid chromatography. Anal Biochem 180, 368-373.

Bhattacharya A, Ramanathan M, Ghosal S \& Bhattacharya SK (2000) Effect of Withania somnifera glycowithanolides on iron induced hepatotoxicity in rats. Phytother Res 14, 568-570.

Bligh EG \& Dyer WJ (1959) A rapid method of total lipid extraction of lipids in tissues. Can J Biochem Physiol 37, 911-917.

Budowski P (1950) Sesame oil. 111. Antioxidant properties of sesamol. J Am Oil Chem Soc 27, 264-267.

Budowski P \& Markley KS (1951) The chemical and physiological properties of sesame oil. Chem Rev 48, 125-151.

Fukuda Y, Nagata M \& Namiki M (1986a) Chemical aspects of the antioxidative activity of roasted sesame seed oil and the effect of using the oil for frying. Agric Biol Chem 50, 857-862.

Fukuda Y, Nagata M, Osawa T \& Namiki M (1986b) Contribution of lignan analogues to antioxidant activity of refined unroasted sesame seed oil. J Am Oil Chem Soc 63, 1027-1030.

Fujiwara FY, Sawada UR, Kuzuyama M \& Igarashi O (1995) Effects of sesamin on fatty acid composition of liver of rats fed $n-6$ and $n-3$ fatty acid rich diet. J Nutr Sci Vitaminol 41, 217-225.

Gao ZL \& Rao EC (1993) Synthesis of formyl (acetyl) amino acid and dipeptide derivatives of amino ketones. Yао Хие Хие Вао 28, 744-757.

Ghafoorunissa, Hemalatha S \& Vishnu Vardhana Rao M (2004) Sesame lignans enhance the antioxidant activity of vitamin $\mathrm{E}$ in lipid peroxidation systems. Mol Cell Biochem (In the Press).

Gu JL, Wakizono Y, Tsujita A, Lim B, Nonaka M, Yamada K \& Sugano M (1995) Effects of sesamin and alpha tocopherol individually or in combination on the polyunsaturated fatty acid metabolism chemical mediator production and immuno globulin levels in Sprague-Dawley rats. Biosci Biotech Biochem 59, 2198-2202.

Gu JY, Tsujitha A, Wakizono Y, Yamada K \& Sugano M (1997) Combined effects of sesamin with alpha tocopherol or tocotrienols on lipid and immune indices in Brown Norway rats. Nutr Res 17, 339-350.

Gu JY, Wakijano Y, Dohi A, Nonaka M, Sugano M \& Yamada K (1998) Effects of dietary fats and sesamin on lipid metabolism and immune function of Sprague-Dawley rats. Biosci Biotech Biochem 62, 1917-1924.

Hemalatha S \& Ghafoorunissa (2004) Lignans and tocopherols in Indian sesame cultivars. J Am Oil Chem Soc (In the Press).

Hirata F, Fujita K, Ishikura Y, Hosada K, Ishikawa $\mathrm{T}$ \& Nakamura H (1996) Hypocholesterolemic effect of sesame lignan in humans. Atherosclerosis 122, 135-136.

Hirose N, Doi F, Ueki T, Akazawa K, Chijiiwa K, Sugano M, Akimoto K, Shimizu S \& Yamada K (1992) Suppressive effect of sesamin against 7,12-dimethyl benzanthracene induced rat mammary carcinogenesis. Anticancer Res 12, $1259-1266$.

Hou RCW, Huang HM, Tzen JTC \& Jeng KCG (2003) Protective effects of sesamin and sesamolin on hypoxic neuronal PC12 cells. J Neurosci Res 74, 123-133.

Hu ML, Edwin NF \& Tappel AL (1990) Effect of dietary menhaden oil and vitamin $\mathrm{E}$ on the in vivo lipid peroxidation induced by iron. Lipids 25, 194-198.

Kamal-Eldin A, Patterson D \& Appelqvist LA (1995) Sesamin (a compound from sesame oil) increases tocopherol levels in rats fed ad libitum. Lipids 10, 499-505.

Kang M, Oaito M, Tsujihara N \& Osawa T (1998) Sesamolin inhibits lipid peroxidation in rat liver and kidney. $J$ Nutr $\mathbf{1 2 8}$, $1018-1022$.

Lueng HW, Vang MJ \& Maris RD (1982) The cooperative interaction between vitamin $\mathrm{E}$ and vitamin $\mathrm{C}$ in suppression of peroxidation of membrane phospholipids. Biochem Biophys Acta 264, 266-272.

Macrae WD \& Towers NGH (1984) Biological activities of lignans. Phytochemistry 23, 1207-1220.

Marklund S \& Marklund G (1974) Involvement of superoxide anion radical in the autooxidation of pyrogallol and a convenient assay for superoxide dismutase. Eur J Biochem 47, $469-474$.

Matsumura Y, Kita S, Morimoto S, Akimoto K, Furuya M, Oka N \& Tanaka T (1995) Antihypertensive effect of sesamin. i. Protection against deoxycorticosterone acetate-salt-induced hypertension and cardiovascular hypertrophy. Biol Pharm Bull 18, 1016-1019.

Matsumura Y, Kita S, Tanida Y, Taguchi Y, Morimoto S, Akimoto K \& Tanaka T (1998) Antihypertensive effect of sesamin. iii. Protection against development and maintenance of hypertension in stroke prone spontaneously hypertensive rats. Biol Pharm Bull 21, 469-473.

Meydani M (1992) Protective role of dietary vitamin E on oxidative stress in aging. Age 15, 89-93.

Miyahara Y, Hibasami H, Katsuzaki H, Imai K \& Komiya T (2001) Sesamolin from sesame seed inhibits proliferation by inducing apoptosis in human lymphoid leukemia molt 4B cells. Int J Mol Med 7, 369-371.

Nakabayashi A, Kitagawa Y, Suwa Y, Akimoto K, Asami S, Shimizu S, Hirose N, Sugano M \& Yamada H (1995) $\alpha$-Tocopherol enhances the hypocholesterolemic action of sesamin in rats. Int J Vit Nutr Res 65, 162-168.

Niederau C, Fischer R, Sonnenberg A, Streemeel W, Trampish HJ \& Strotimeye G (1985) Survival and causes of death in cirrhotic and in non cirrhotic patients with primary hemochromatosis. $N$ Engl J Med 313, 1256-1262.

Paglia DE \& Valentine WN (1967) Studies on the quantitative and qualitative characterization of erythrocyte glutathione peroxidase. J Lab Clin Med 70, 158-169.

Parker SP, Timothy JS \& Joy ES (2000) Cytochrome P450 3A-dependent metabolism of tocopherols and inhibition by sesamin. Biochem Biophys Res Commun 277, 531-534.

Press M, Hartop PJ \& Proney C (1974) Correction of essential fatty acid deficiency in man by cutaneous application of sunflower seed oil. Lancet 1, 597-598.

Pulla Reddy ACH \& Lokesh BR (1994) Effect of dietary tumeric (Curcuma longa) on iron-induced lipid peroxidation in the rat liver. Food Chem Toxicol 32, 279-283.

Reeves PG, Nielsen FH \& Fahey GC (1993) AIN-93 purified diets for laboratory rodents. J Nutr 123, 1939-1951.

Satchithanandam S, Chanderbhan R, Kharroubi AT, Calvert RJ, Klufold D, Tepper SA \& Kritchevsky D (1996) Effect of sesame oil on serum and liver lipid profile in the rat. Int $J$ Vit Nutr Res 66, 386-392.

Schacterle GR \& Pollack RL (1973) A simplified method for the quantative assay of small amounts of protein in biologic material. Anal Biochem 51, 654-655.

Scholz KS, Liken AD, Gumpricht E \& Reddy CD (1997) Glutathione dependent factors and inhibition of rat liver microsomal lipid peroxidation. Free Radic Biol Med 23, 815-828.

Slater TF \& Sawyer BC (1971) The stimulatory effects of carbon tetrachloride and other halogeno-alkanes on peroxidative reactions in rat liver fractions in vitro. Biochem J 123, 805-814.

Sugano M, Inoule T, Koba K, Yoshida K, Hirose N, Shinmen Y, Akimoto K \& Amachi T (1990) Influence of sesame lignans on various lipid parameters in rats. Agric Biol Chem 54, 2669-2673.

Sugano M \& Akimoto K (1993) Sesamin: a multifunctional gift from nature. J Chin Nutr Sci 18, 1-11.

Uchida M, Nakajin S, Toyoshima S \& Shinoda M (1996) 
Antioxidant effect of sesamol and related compounds on lipid peroxidation. Biol Pharm Bull 19, 623-626.

Yamashita K, Ikeda S, Lizuka Y \& Ikeda Y (2002) Effect of sesaminol on plasma and tissue $\alpha$-tocopherol and $\alpha$ tocotrienol concentrations in rats fed a vitamin $\mathrm{E}$ concentrate rich in tocotrienols. Lipids 37, 351-358.

Yamashita K, Kagaya M, Higuti N \& Kiso Y (2000) Sesamin and $\alpha$-tocopherol synergistically suppress lipid peroxide in rats fed a high docosahexaenoic acid diet. Biofactors 11, 11-13.

Yamashita K, Lizuka Y, Imai T \& Namiki M (1995) Sesame seed and its lignans produce marked enhancement of vitamin $\mathrm{E}$ activity in rats fed a low tocopherol diet. Lipids 30, 1019-1028.

Yamashita K, Nohara Y, Katayama K \& Namiki M (1992) Sesame seed lignans and $\gamma$-tocopherol act synergistically to produce vitamin $\mathrm{E}$ activity in rats. $J$ Nutr 122, 2440-2446.

Zhu QY, Huang YY \& Chen ZY (2000) Interaction between flavonoids and a tocopherol in human low density lipoprotein. J Nutr Biochem 11, 14-21. 